Artigo original

Hegemonia - Revista Eletrônica de Relações Internacionais do Centro

Universitário Unieuro

ISSN: $1809-1261$

UNIEURO, Brasília, número 16, 2015, pp. 22-45.

Recebido em: 19/2/2015

Avaliado em:10/3/2015

Aprovado em: 28/4/2015

\title{
A CONSTRUÇÃO E OS USOS DO CONCEITO DE DIREITOS HUMANOS ATRAVÉS DO RAP EM UMA PENITENCIÁRIA:
}

\section{UMA BIOPOLÍTICA DO ISOLAMENTO}

Priscila de Oliveira Xavier Scudder, 1 Vinícius Comparini Arcolino2, e Rogério Mendes

de Oliveira3

RESUMO: O presente artigo apresenta um diagnóstico sobre o modo como o Rap tem se constituído em ferramenta de apropriação e mobilização do conceito de direitos humanos em uma penitenciária. A partir das narrativas de prisioneiros confinados na Penitenciária Major Eldo de Sá Correia, em Rononópolis/MT, e de sua relação com a letra da musica "Barril de Polvora" do grupo de Rap Demonstro, foi possível perceber o potencial politico e social mobilizado por este estilo musical. Considerando que as narrativas de prisioneiros são, via de regra, ignoradas como fontes históricas legítimas, este artigo, ao registrá-las, indica que a escuta de suas vidas, ouvidas com a perspectiva otobiográfica, apresenta experiências com as quais podemos aprender. De outro modo ao conferir-Ihes tratamento academico, acabamos por compor um arquivo de história oral, e tornamos suas versões sobre

1 Doutora em Educação- Professora Adjunta do Departamento de História da Universidade Federal de Mato Grosso. Coordenadora do Grupo de Pesquisa - "Observatório: Poder, Cultura e Contemporaneidade". Com pesquisas na área de Violência, Direitos Humanos, Sistema Prisional.

2 Estudante de Psicologia - Bolsista PIBIC - no Projeto de Pesquisa - "Diagnóstico dos Fazeres e Poderes-Saberes que Constituem a Existência no Centro Sócioeducativo e Prisões de Rondonópolis - MT"/ Registro Propeq/UFMT: 053/CAP/2014, coordenado pela Profa. Dra. Priscila de O. X. Scudder.

3 Estudante de Geografia - Bolsista PIBID - Voluntário no Projeto de Pesquisa - "Diagnóstico dos Fazeres e Poderes-Saberes que Constituem a Existência no Centro Sócioeducativo e Prisões de Rondonópolis - MT"/ Registro Propeq/UFMT: 053/CAP/2014, coordenado pela Profa. Dra. Priscila de O. X. Scudder. 
Artigo original

Hegemonia - Revista Eletrônica de Relações Internacionais do Centro Universitário Unieuro

ISSN: $1809-1261$

UNIEURO, Brasília, número 16, 2015, pp. 22-45.

a maquinaria punitiva em documentos e ciência.

Palavras-chave: Rap, Prisão, Direitos Humanos.

ABSTRACT: This paper presents an assessment of how Rap has become an ownership and mobilization tool of the concept of human rights in a penitentiary. From the accounts of prisoners confined in the Penitentiary Major Eldo Correia de Sá, in Rononópolis / MT, and its relationship with the lyrics of the song "Powder Keg by Rap Demonstro, it was revealed the political and social potential mobilized by this musical style. Whereas the accounts of prisoners are usually ignored as legitimate historical sources, this paper, to record them indicates that listening to their lives, heard with otobiographical perspectives, presents experiences with which we can learn. Otherwise, given typical academic treatment, the accounts end up composing an archive of oral history and become their versions on the punitive machinery in documents and science.

Keywords: Rap, Prison, Human Rights.

Introdução

Ao longo de nossa pesquisa na Penitenciária Major Eldo de Sá Correia em Rondonópolis/MT, popularmente denominada de Mata Grande, registrando narrativas de prisioneiros, refletindo sobre o racismo institucional, observando os discursos da segurança pública e das mídias baseados em clichês como "direitos humanos só serve prá defender bandido", diagramar as ferramentas que "traduziam" o conceito para os prisioneiros, pareceu-nos uma maneira razoável de interrogá-lo, ou melhor interrogar seu duplo uso, ora como ferramenta de combate aos crimes cometidos pelo Estado, ora como componente frequente em discursos racistas, classsistas e segregacionistas.

Refletir sobre Direitos Humanos no Sul do Planeta, neste lugar geopolítico e cultural em que nossa vida se articula, denominado unilateral e "interesseiramente" de "Terceiro Mundo", é deveras pertinente. 
Artigo original

Hegemonia - Revista Eletrônica de Relações Internacionais do Centro Universitário Unieuro

ISSN: $1809-1261$

UNIEURO, Brasília, número 16, 2015, pp. 22-45.

Aos que se ocupam do tema, não escapa o sensível aumento da produção intelectual sobre Direitos Humanos nas últimas décadas. Esta crescimento quantitativo, por um lado, pode ser explicado pelo crescimento constante das violações dos direitos individuais por parte dos Estados. De outro lado, além disto esta produção se tornou em boa parte sinônimo de "Direito Internacional dos Direitos Humanos", assim como também não escapa aos pesquisadores do tema o caráter predominantemente pacífico que se atribui a evolução do conceito de direitos humanos.

No nível acadêmico a produção de maior volume, em geral, tem ficado circunscrita ao mundo universitário, que em geral, pensa o conceito tendo como referência o documento de Helsinque o que parece-nos perigoso, especialmente porque parte do conteúdo de onde parte, é deveras, questionável. Ora, Noberto Bobbio, lembra que

Declaração [Universal dos Direitos Humanos], conserva um eco... qual seja, os homens não nascem livres, nem iguais [... ] a liberdade e a igualdade dos homens não são um dado de fato, porém um ideal que deve ser perseguido, não uma existência, porém um valor; não um ser, mas um dever [...]. (BOBBIO, 34).

A afirmação deste nascimento igualitário de todos esconde ainda o fato de que "não existe direito que, no seu início, não fosse abuso, usurpação e violência." (NIETZSCHE, 2009:60). Entre tantas coisas, buscamos neste artigo, valer-nos de práticas cotidianas, comuns, que oferecem outra perspectiva e possibilidade de pensar o conceito, e afinal, como alertava Nietzsche, uma das tarefas da filosofia seria

acentuar a relatividade de todo conhecimento e seu antropomorfismo, assim como a força da ilusão, dominante em toda parte. Feito isso não pode mais reter o instinto desenfreado do conhecimento que consiste, sempre mais, em julgar segundo o grau de certeza e em procurar objetos 
Artigo original

Hegemonia - Revista Eletrônica de Relações Internacionais do Centro Universitário Unieuro

ISSN: $1809-1261$

UNIEURO, Brasília, número 16, 2015, pp. 22-45.

cada vez mais pequenos. (NIETZSCHE, 2007:22).

Esses objetos pequenos podem ser encontrados nas razões que levam a criação de determinados conceitos, nos interesses que movem discursos, legitimam colonialismos e instauram práticas excludentes, nos silenciamentos e artimanhas.

Entre as práticas cotidianas que constroem a noção de direitos humanos a partir da diferença, da vida, do corpo e daquilo que diz respeito à conservação da vida, identificamos a música, em especial, o movimento Hip Hop. O modo como articula práticas de direitos humanos, se distancia da noção corrente de que 0 desenvolvimento do conceito tem origem em um extraordinário consenso universal, algo como uma condição inerente da humanidade, um pacto naturalmente acordado. Pelo contrário, ao tratar das coisas da vida, os interesses políticos e econômicos presentes na criação do conceito são evidenciados, recuperando assim sua capacidade de mobilização social.

Desta forma, consideramos que o movimento hip-hop, apesar de nascido fora da academia, contribui de forma importante para pensarmos Direitos Humanos, a partir do Sul, da perspectiva de descolonização do pensamento dos conceitos. Neste sentido, dar tratamento acadêmico ao hip hop, é entre outras coisas, lutar contra aquilo que Grosfoguel denomina de racismo epistêmico, ou seja, contra a afirmação da inferioridade das epistemologias e cosmologias nãoocidentais pelo discurso euroamericano, que visa, entre outras coisas, impor a epistemologia ocidental como forma superior e única fonte para definir os direitos humanos, a democracia, a cidadania, etc.

A maneira como o Hip Hop, seja através da música, da dança e/ou do grafite encontra eco e informa sobre a vida para os prisioneiros, fez com que começassemos a investigar o que constituia sua força. 
Artigo original

Hegemonia - Revista Eletrônica de Relações Internacionais do Centro Universitário Unieuro

ISSN: $1809-1261$

UNIEURO, Brasília, número 16, 2015, pp. 22-45.

movimento cultural Hip Hop:

É quase unânime a definição de Hip Hop como um movimento ou uma cultura difundida em quatro elementos,que apresentaremos detalhes adiante, mas sua concepção é muito mais ampla, subjetiva e complexa. Segundo Schober (2014):[isp]

O hip-hop é tão urbano quanto as grandes construções de concreto e as estações de metrô, e cada dia se torna mais presente nas grandes metrópoles mundiais. No Brasil, é a voz cantada dos presídios, está nos grafites que embelezam ou enfeiam muros e paredes das grandes cidades, nas roupas da juventude, é um movimento que invade as metrópoles brasileiras da periferia para o centro. Para muitos jovens, o hip-hop vem fazendo a diferença, mudando jeitos de pensar, dando oportunidades e denunciando a desigualdade social e racial.

A definição do Hip Hop não é simples. Desde seu inicio na década de 70 a constante evolução de suas vertentes e seu caráter ideológico, fizeram com que o enquadramento solidificado em um conceito fosse algo complexo. Para ROCHA et al. (2001), "A definição conceitual do hip hop ainda é problemática. Rappers, b.boys, grafiteiros, Djs e estudiosos acadêmicos do tema sabem dizer o que faz ou não parte do hip hop e avaliar sua importância para a juventude excluída" mas basicamente o Hip Hop é um movimento que engloba o Rap (ritmo e poesia) executado por um MC (Mestre de Cerimônia); Djs (Disc-jóqueis, que tocam as bases musicais dando suporte para o mc cantar/falar o rap); Grafite (Pintura urbana feita pelos grafiteiros) e o Break Dance (estilo de dança executado pelos B.boys e B.Girls) sisp:

Em sua tese, "Movimento negro juvenil: Um estudo de caso sobre jovens 
Artigo original

Hegemonia - Revista Eletrônica de Relações Internacionais do Centro Universitário Unieuro

ISSN: $1809-1261$

UNIEURO, Brasília, número 16, 2015, pp. 22-45.

rappers de São Bernardo do Campo (1996)", a educadora Elaine Nunes de Andrade sugere que:

(...) originalmente, o hip hop é um conjunto de manifestações culturais: um estilo musical, o rap; uma maneira de apresentar essa musica em shows e bailes que envolve um DJ e um MC; uma dança, o Break; e uma forma de expressão plástica, o grafite. Também cabe, portanto, a caracterização do hip hop como uma cultura de rua, que é o conceito mais utilizado pelos seus próprios integrantes. Embora os hip hopers também aceitem a idéia de movimento social, quando solicitados a responder "o que é o hip hop", a primeira definição que surge é "uma cultura de rua formada por quatro elementos artísticos: o break, o rap, o grafite o DJ e o MC."

Foi nos Estados Unidos, em Nova York, mas precisamente no sul do Bronx, o berço para o nascimento do Hip Hop, porém suas raízes vêm da Jamaica. Desde a década de 40 festas e bailes de rua eram realizadas nos bairros carentes das principais cidades da ilha, ao som do Ska, Reggae, Raggamuffin, Dub, entre outros ritmos jamaicanos. No inicio de 1970 uma grande crise econômica abalou a pequena ilha e houve uma grande migração desses Djs e músicos para os Estados Unidos em busca de melhores condições de vida. Por outro lado os americanos vinham abalados da enorme crise mundial de 1929 fazendo com que desde esse período muitos dançarinos de cabarés e músicos desempregados fossem ganhar a vida nas ruas.

Segundo Leon (2010) houve uma fusão cultural que começou a se manifestar através da arte no inicio dos anos 70 nos guetos de Nova Iorque onde a maior parte da população era negra ou mestiça, principalmente no Bronx, local onde se instalaram a maioria dos novos imigrantes. Músicos jamaicanos acostumados a realizar os bailes de rua nos bairros carentes de Kingston se 
Artigo original

Hegemonia - Revista Eletrônica de Relações Internacionais do Centro Universitário Unieuro

ISSN: $1809-1261$

UNIEURO, Brasília, número 16, 2015, pp. 22-45.

juntaram a jovens negros americanos e deram início ao Rap. Dançarinos de rua ao som do Funk Soul (ritmo muito influente do povo negro no inicio da década de 70, principalmente pela voz James Brown) iniciaram o Break Dance, e jovens motivados por uma vontade de identificação e inserção social, através da arte, começaram a pintar com latas de spray os vagões de trens com suas tags e bombs (formato de letra que identifica um grafiteiro/pixador), com nomes ou apelidos originando o Grafite Neste contexto, nasciam diferentes manifestações artísticas de rua, formas próprias dos jovens ligados aquele movimento social que nunca deixou de ser cultural e artístico nas formas de fazer música, dança, poesia e pintura. Os DJs Afrika Bambaataa, Kool Herc, Grand Máster Flash, Grand Wizard Theodore, Grandmixer DST (Hoje DXT), Hollywood e Pete Jones, entre outros observaram e participaram destas expressões de rua, e começaram a organizar festas nas quais estas manifestações tinham espaço (Lion, 2010).

O Hip Hop se expandiu para o mundo todo, fazendo parte da cultura de vários países. No Brasil consolidou raízes muito fores desde o final da década de 70 e inicio de 80 em São Paulo e Rio de Janeiro, sendo parte de uma enorme herança cultural disseminada para grande parte do interior do país, se fortalecendo cada vez mais em dias atuais

O Rap no Brasil

No Brasil, especificamente em São Paulo, o Rap e o Hip Hop se desenvolveram em meados dos 1980 através de encontros de jovens de periferia nas Praças da Sé e Roosevelt, no Vale do Anhangabaú, nas ruas Dom José de Barros, 24 de Maio e na Estação São Bento do Metrô. Muitos Jovens moradores das periferias de São Paulo, nos finais de semana, assistiam e participavam dos encontros comandados pelo breaker Nelson Triunfo (2015). 
Artigo original

Hegemonia - Revista Eletrônica de Relações Internacionais do Centro Universitário Unieuro

ISSN: $1809-1261$

UNIEURO, Brasília, número 16, 2015, pp. 22-45.

Nesses espaços surgiu o "tagarela", primeiro nome dado ao que viria ser o Rap. A partir do encontro de Thaíde, Dj Hum, Mano Brown, Ice Blu, Edi Rock e DJ KI Jay, Os metralhas, entre outros grandes ícones do Rap Nacional que começa a surgir uma cena do estilo musical no Brasil.

"O Rap, a principio chamado de "tagarela", ascende e os breakers formam grupos de Rap. Em 1988 foi lançado o primeiro registro fonográfico de Rap Nacional, a coletânea "Hip-Hop Cultura de Rua" pela gravadora Eldorado. Desta coletânea participaram Thaide \& DJ Hum, MC/DJ Jack, Código 13 e outros grupos iniciantes." (Hip Hop ."Historia do RAP'. ://www.wooz.org.br/musicarap.htm 21 Abril 2015)

No Rio de Janeiro no final da década de 80 e inicio de 90 também começava a construção de uma forte cena do Rap. Gabriel Pensador lançou seu primeiro single "Tô Feliz (Matei o Presidente)" em 1992, MV Bill participou de uma coletânea chamada "Tiro Inicial" em 1993 , apesar de seu primeiro álbum só ter sido lançado em 1999. Também em 1993 Black Alien e Speed, dois mc's formando uma dupla muito original que misturava Rap com Ragga (ritmo jamaicano) entre outros ritmos foram grandes influências para o movimento, no mesmo período a banda Planet Hemp que misturava Rap com Rock e outros estilos também surgia no Rio de Janeiro com um som pesado e letras fortes tematizando problemas sociais, cotidiano das ruas e a bandeira da legalização da maconha.

Em Sobradinho, cidade satélite de Brasília Genival Oliveira Gonçalves o GOG iniciou seus trabalhos com o Hip Hop em 1991 e em 1992 lançou seu primeiro disco intitulado "Peso Pesado". GOG apesar de não ser parte do eixo Rio São Paulo, foi e ainda é um grande ícone da Cultura Hip Hop, militante do movimento negro e a inspiração para muitos jovens de todo o Brasil.

Um nome de forte influência no Rap nacional foi Mauro Matheus, conhecido como Sabotage. Este é unanimidade entre vários $\mathrm{mc}^{\prime} \mathrm{s}$ como um dos mais 
Artigo original

Hegemonia - Revista Eletrônica de Relações Internacionais do Centro Universitário Unieuro

ISSN: $1809-1261$

UNIEURO, Brasília, número 16, 2015, pp. 22-45.

importantes da história do Rap, lançou apenas um disco em 2001 chamado "O Rap é Compromisso". Com sua forma diferenciada de rimar e personalidade carismática, Sabotage revolucionou o Rap chegando a lugares como em Miami para receber o prêmio no festival de cinema brasileiro de melhor trilha sonora do filme "O Invasor" de Beto Brant, na qual o Rapper também tem uma pequena atuação. No filme "Carandiru" de Hector Babenco, Sabotage tem uma participação mais incisiva como ator, encarna o personagem "Fuinha" um traficante de drogas confinado na casa de detenção que dá nome ao filme. Sabotage foi assassinado em 2003, ainda jovem e com apenas um disco lançado, Sabotage se eternizou e virou um ícone para toda uma geração do Rap nacional. No inicio de 2015 foi lançado o documentário "Sabotage: o Maestro do Canão" do diretor Ivan 13P, contando sua historia:

Desde os últimos anos até dias atuais o Rap vem se fortalecendo cada vez mais. A tecnologia, a facilidade de trabalhar na produção musical e a diminuição dos espaços que a internet possibilita, fez com que vários novos grupos musicais de Rap de todo o Brasil tivessem oportunidade de realizar seus trabalhos e divulgálos. Aliado a isso, grandes nomes do Rap nacional como Racionais Mc's, Gabriel Pensador, RZO, Rappin Hood, Dexter, Black Alien, Marcelo D2, B-negão, Planet Hemp, GOG, Facção Central, MV Bill entre outros ainda estão tocando e produzindo novos trabalhos em dias atuais

\section{AâiInstituição Prisão e o Rap}

O lugar geográfico onde nasce o Rap é o mesmo lugar onde o poder panóptico captura a maioria dos homens, mulheres e adolescentes encarcerados. Esta comunhão geográfica parece confirmar a afirmação de que 
Artigo original

Hegemonia - Revista Eletrônica de Relações Internacionais do Centro Universitário Unieuro

ISSN: $1809-1261$

UNIEURO, Brasília, número 16, 2015, pp. 22-45.

Por ser uma música surgida entre a população pobre, o rap tem, na grande massa carcerária brasileira, composta majoritariamente de negros e pobres, um público fiel e rapper em potencial. O movimento é de mão dupla: o rap tematiza o mundo da cadeia, ponto final daqueles que se envolvem com o crime e com a violência - ameaça vivida de forma próxima e intensa por grande parte dos moradores da periferia -, e as prisões produzem rap. (ZENI, B 2004, p. 225).

O Rap nasceu na periferia, e hoje após 35 anos de sua chegada no Brasil, continua retratando, relatando e dando voz a esses marginalizados, negros, pobres que via de regra são silenciados pela sociedade, seja por sua cor, local de moradia ou em função do encarceramento. ispp?

A prisão, por outro lado, desde sua origem neste País em 1769 quando a Carta Régia do Brasil determinou a construção da primeira prisão brasileira, a Casa de Correção do Rio de Janeiro, vem servindo para o controle social mediante o exercício de um poder que se faz cada vez mais opressor e violento sobre a mesma periferia em que o Rap se consolidou. Michel Foucault em Vigiar e Punir (1987: 195), abre a quarta parte do livro da seguinte maneira;

sygge..) A forma-prisão preexiste à sua utilização sistemática nas leis penais.

Ela se constitui fora do aparelho judiciário, quando se elaboraram, por todo corpo social, os processos para repartir os indivíduos, fixá-los e distribuí-los espacialmente, classificá-los, tirar deles o máximo de tempo e o máximo de forças, treinar seus corpos, codificar seu comportamento continuo, mantê-los numa visibilidade sem lacuna, formar em torno deles um aparelho completo de observação, registro e notações, construir sobre eles um saber que se acumula e se centraliza. A forma geral de uma aparelhagem para tornar os indivíduos dóceis e úteis, por meio de um trabalho preciso sobre seu corpo, criou a instiuição-prisão, antes que a lei a definisse como a pena por excelência (..) 
Artigo original

Hegemonia - Revista Eletrônica de Relações Internacionais do Centro Universitário Unieuro

ISSN: $1809-1261$

UNIEURO, Brasília, número 16, 2015, pp. 22-45.

Dessa forma, é possível pensar que as relações de poder que se estabelecem no espaço da periferia se constituem como uma prisão, muito antes da lei institucionalizá-la. A classificação econômica, forma de fixar e distribuir espacialmente os indivíduos sugando seu tempo, sua força de trabalho, resultante do treinamento de seus corpos, forma em torno deles todo um aparato completo de observação. É em função desse cenário que talvez o Rap e a prisão se estabeleceram baseados em uma relação de intimidade e reciprocidade, como apontou Zeni (2004). O Rap tematiza o universo da cadeia, onde estão majoritariamente os mesmos pretos e pobres da periferia onde o estilo musical teve sua origem e, por outro lado as cadeias produzem Rap:sep?

Os grupos 509 E e Detentos do Rap, foram os dois principais grupos de Rap dos que gravaram discos e fizeram shows ao mesmo tempo que estavam vivendo dentro de uma penitenciaria, no caso, a Casa de Detenção de São Paulo, o Carandiru. Por mais que o Rap e as prisões sempre estivessem interligadas espacialmente e historicamente é com esses dois grupos que o estilo musical e a instituição de fechamento se fundem de forma mais intima Um pouco antes desses dois grupos o Carandiru já havia se encontrado com o Rap na figura de Jocenir, um detento que juntamente com Mano Brown (Racionais) compôs a musica "Diário de um Detendo" uma das primeiras, se não a primeira vez que o Rap descreve de forma mais literal a vivência de um detento, dando voz aqueles que não tinham espaço para falar, como indiga Mano Brown:

(...)O Carandiru é a veia do Hip Hop. O Carandiru é a veia do hip hop, porque aqui se faz música. "É aqui que você vai me encontrar, junto da realidade", afirma Mano Brown. Ele já foi a voz da Casa de Detenção, quando cantou "Diário de um detento", no CD Sobrevivendo no inferno, música composta em parceria com Jocenir, um "tiozinho" que cumpria pena na casa de detenção: Cada detento uma mãe, uma crença/ Cada crime uma sentença/ Cada sentença um motivo, uma história de lagrima, 
Artigo original

Hegemonia - Revista Eletrônica de Relações Internacionais do Centro Universitário Unieuro

ISSN: $1809-1261$

UNIEURO, Brasília, número 16, 2015, pp. 22-45.

sangue, vidas e glórias/Abandono, miséria, ódio, sofrimento,desprezo, desilusão, ação do tempo/ Misture bem essa química, pronto:eis um novo detento. Jocenir não ficou só nessa parceira com Brown e em 2001 publicou o livro "Diário de um Detento: o livro"." (ROCHA et. al 1996, p72.)

Dexter e Afro X eram dois dos outros 7.000 homens presos no Carandiru. Antes de serem detidos já cantavam Rap. Dexter fazia parte do grupo "Tribunal Popular" e Afro X do "Suburbanos". Na penitenciaria esses dois Mc's se uniram e formaram o 509-E (o nome vem do numero da cela que dividiam no Pavilhão 7). Em 2000 lançaram seu primeiro disco denominado "Proverbios 13"com a produção de Edy Rock, Mano Brown ( ambos dos Racionais mc's) Dj Hum e MV Bill šbgrupo fez varias apresentações, ganhou prêmios como Hutúz de grupo revelação do ano no Rio de Janeiro. Em 2000, participaram de programas de televisão, lançaram outro trabalho intitulado "MMII DC (2002 Depois de Cristo)". ,em 2003 por vários motivos entre eles brigas e discordâncias internas o grupo terminou.

No ano de 2009, foi lançado um documentário sobre o 509-E chamado "Entre a Luz e a Sombra" dirigido por Luciana Burlamaquijâpesar de uma maior visibilidade e fama o 509-E não foi o primeiro grupo de Rap a ser formado dentro de uma penitenciaria. Na mesma casa de detenção o "Detentos do Rap" formado por Ronaldo Silva (MC Roni), Eduardo Fonseca (Do Rap) e Daniel Sancys haviam lançado um disco em 1998 chamado Apologia ao Crime, e o Pesadelo Continuaem 1999. "No Detentos do Rap todos são Mc's e compõe, o Dj é chamado apenas para os dias de apresentações. Segundo Dexter, os Detentos foram uma referência porque os caras fizeram sucesso rimando do xadrez. Então se agente der um gás, também vamos conseguir"( ROCHA et. al 1996, p78). Em 2012 o grupo lançou seu ultimo álbum intitulado "Eternamente

O Carandiru, porém, não é o único cenário musical do universo carcerário. 
Artigo original

Hegemonia - Revista Eletrônica de Relações Internacionais do Centro Universitário Unieuro

ISSN: $1809-1261$

UNIEURO, Brasília, número 16, 2015, pp. 22-45.

Vários outros Rap's já foram feitos dentro do ambiente de cárcere, em parceria com alguém de dentro, ou simplesmente mc's que relatem de fora essa realidade. Tanto nas parcerias com presidiários, como em composições que retratem o cotidiano de uma penitenciaria tem-se em Rondonópolis, Mato Grosso o grupo de Rap Demonstro:

Historia do Grupo Demonstro:

A partir da entrevista realizada em 28 de Abril de 2015 com o Mc Hugo Projetista, um dos fundadores do Demonstro foi possível ter acesso a historia deste grupo que é pioneiro no cenário Hip Hop na cidade de Rondonópolis.

Segundo Hugo, o Demonstro é um grupo de Rap que nasceu em 2006 da junção de três grupos, o "Terapia" composto por Mc Mano e Dj Cabeça, "Raciocínio vs Sistema" formado por Hugo Projetista, Zaqueu e Lila e o "Verbo Hediondo" formado por Emerson Salomão. Nesse ano o "Raciocínio vs Sistema" fez uma apresentação no cais de Rondonópolis e após essa apresentação um conhecido de Hugo o convidou para gravar umas musicas, como o grupo só tinha uma musica, o Hugo foi conversar com o $\mathrm{Dj}$ Cabeça e com o Mano para fazerem esse trabalho juntos, Hugo chamou também o Emerson Salomão e formaram o Demonstro. Esse nome veio de uma idéia do Dj Cabeça, foi a junção do nome que se dá a um cd de demonstração, abreviado como "demo", com a idéia falar, mostrar alguma coisa, daí Demonstro. Essa gravação acabou sendo de uma musica que já existia, composta por Mc Mano, chamada "Barril de Polvora", foi a primeira música lançada pelo grupo. Logo no inicio da banda, ainda no ano de 2006 o grupo começou a realizar trabalhos de ressocialização na penitenciaria Major Eldo de Sá Corrêa conhecida como Mata Grande, e por muito tempo aquele ambiente foi um dos poucos que o grupo tinha para realizar um trabalho e tocar, levando a musica, não 
Artigo original

Hegemonia - Revista Eletrônica de Relações Internacionais do Centro Universitário Unieuro

ISSN: $1809-1261$

UNIEURO, Brasília, número 16, 2015, pp. 22-45.

só o Rap mais variados outros estilos que o Dj tocava quando os presos pediam para ouvir.

Foi um trabalho realizado durante seis anos, até 2012, quando houve alternância na direção na penitenciaria, o que implicou em várias mudanças, entre elas o fim do trabalho do Demosntro no interior da cadeia.

Em 2014 o grupo lançou seu primeiro cd intitulado "Rondonópolis apresenta sua cria", e neste ano de 2015 está em estúdio com outro trabalho.

No final de 2014 o Dj Cabeça faleceu e atualmente o grupo é formado por Dj Zaqueu, mc's Hugo Projetista, Mano e Lila.

Segundo Hugo, o universo do Rap sempre esteve muito próximo com o da cadeia, por isso vários outros grupos de Rap mais antigos têms música que falam sobre essa realidade. Cita como exemplo: Realidade Cruel, Faç̧ão Central, Racionais, Faces da Morte por essa proximidade mesmo entre esses dois mundos.

Com o Demonstro não foi diferente, a primeira música que o grupo gravou e lançou foi a "Barril de Pólvora" composta pelo Mc Mano, nela retrata pelo olhar de fora o cotidiano, os problemas e as vivências dos presidiários no interior da Mata Grande. Segundo Mano a musica não é algo posísvel de explicar, tampouco o processo de composição. A letra e a idéia já falam por si só. săjssim, apresentamos a letra damúsica Barril de Pólvora:

Presídio da Mata Grande campo de concentraçãoşąarril de pólvora, castelo do cão, penitenciaria de meio porte, várias fugas várias morteșilata Grande somente sofrimentóşanho de sol cela cheia e vários linchamentoss muitos estão pagando os crimes cometidossirtigo 12 ,

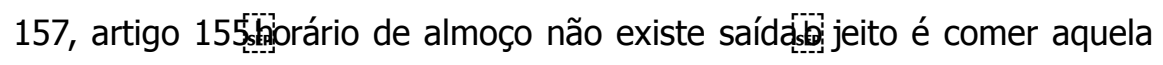
comida que nem porco comeria sishegados contaminados com vírus HIV, fim da vida prestes a morretsum dia aqui mais parece um anos trocando uma idéia pro tempo passar voandospra dormir um sufoco danados obrigados a dormir todos amontoados sardinha vivem 
Artigo original

Hegemonia - Revista Eletrônica de Relações Internacionais do Centro Universitário Unieuro

ISSN: $1809-1261$

UNIEURO, Brasília, número 16, 2015, pp. 22-45.

espremidojalas pra 6 manos tem mais de 25s sem contar a latrina que

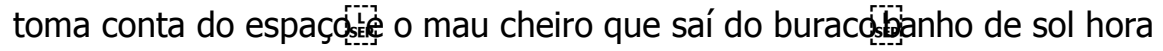
de ganhar dinheirds dender cigarro drogas objetos pontiagudoss submundo com um radio de pilhasuma roda é formada pra curtir um racionais ( homem na estrada) mais uma fuga por debaixo dos panosse tentar fugir e não

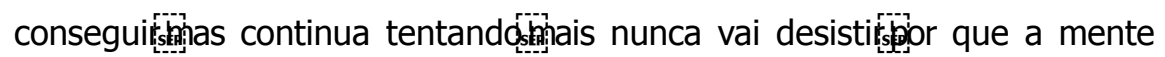

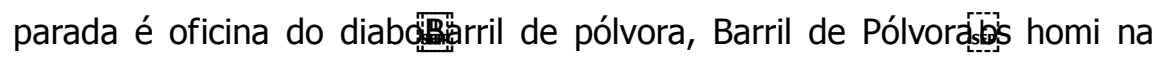
nossa coldes parril de pólvora, Barril de Pólvordspra viver la dentro tem que

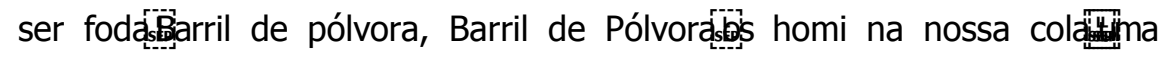
reunião é formada entre celas rivaișisbjetivo impera a paz (imperar a paz o caralho suluma emboscada na certa era pra ser três somente um morreu na celabs outros dois conseguiu escaparspulando o alambrado salvado sua vidassigé Afonso pagou 6 anos no presídio e por vacilo foi morto pelos próprios amigoss pela policia seu corpo foi recolhidods lireção IML tudo por conta do peritósesultado da autópsiajkjarais estacadas no peito estacada nas costas corpo velado no Monte Líbanos agora passa a informação (morre mais um detento na casa de

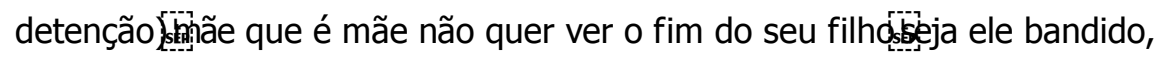
pra ela é um bom meninosgue diferença faz pra sociedadês morre um dois trêsisho xadrez cagueto vai morrer não existe piedade essa é a lei do xadrez pra caguetagend tem a língua comprida já erds juiz la dento é os velhos de celds sentença que impera é somente a mortestum primário caiu acusação (é um estuprador)s] vai sentir a mesma dor da vitima que

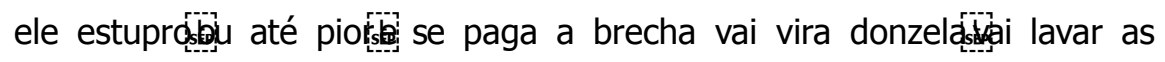
roupas dos detentos la na celds ser enrrabado toda noite pelos camaradas tiver a sorte pra ter a vida poupadus beçabeça e peras raspadasfifm de semana casa cheia muito sofrimentósthoro de filho pra mãe e arrependimentơs seu filho ou parente que esta trancafiado filho abraça seu pai, um

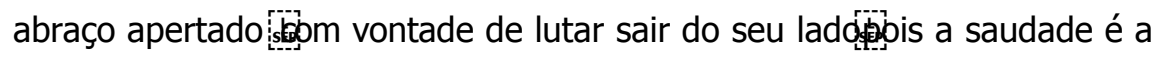
única coisa que restáspra ter força de vontade querer sair o mais 
Artigo original

Hegemonia - Revista Eletrônica de Relações Internacionais do Centro Universitário Unieuro

ISSN: $1809-1261$

UNIEURO, Brasília, número 16, 2015, pp. 22-45.

depressabe quando a sirene toca, fim da visitas na mente o semblante daqueles qficds de outubro dia das crianças seu filho vai ficara somente na esperançastêzando pra deus que te proteja deste inferno vivofezando pra deus que te proteja de todos os perigoss que ele mais quer é seu pai do seu ladóste dar uma força reconstruir o barracosjer levado pra escola. ses nos fim de semanas com o pai bater uma boldsdepois de muitos anos sua pena e cumprida em liberdade pra seguir a sua vidáspis todos merecem uma segunda chanceshais a sociedade acha 0 bastantêfecha as portas vira as costasstiatam o ex detento como se fosse

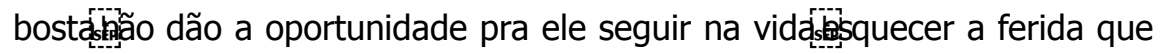

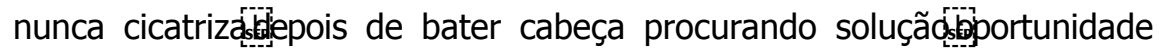
não é oferecida pra quem sai da prisãófểcha as portas. de Charles Stanley Silva Pereira, morador da ala dos trabalhadores na casa de detenção Major Eldo Sá Correa (Mata Grande)

No dia 18 de março de 2015 em uma de nossas visitas a Mata Grande em decorrência da realização de pesquisa acadêmica, comentei com um agente penitenciário que nos acompanhava, que gostaria de conversar com algum preso diagnosticado como doente mental. Fui informado que havia apenas um detento nessa condição com quem poderia fazer contato, pois assim como os demais ele era considerado muito "agressivo".

Este preso estava mais acessível, pois ficava isolado em uma cela ao lado da ala dos trabalhadores. Fui encaminhado até ele e perguntei se gostaria de conversar comigo. Lembro-me de suas palavras: se for pra conversar como homem, com respeito não tem problema nenhum, converso numa boa.Sentei-me em frente sua cela e disse-lhe que poderia falar livremente, sobre o que quisesse e tivesse desejo, ali conversamos por um tempo.

Nesse meio tempo um detento da ala dos trabalhadores me ofereceu água, agradeci e ele me levou água gelada em uma garrafa pet juntamente com uma caneca de plástico azul. Com aspecto sorridente e descontraído me perguntou o 
Artigo original

Hegemonia - Revista Eletrônica de Relações Internacionais do Centro Universitário Unieuro

ISSN: $1809-1261$

UNIEURO, Brasília, número 16, 2015, pp. 22-45.

que estava fazendo ali, disse que estava escutando as narrativas daquele preso, e ele indagou, mas é pra falar sobre o que? Respondi que era pra falar sobre o que ele quisesse, expliquei que não tinha perguntas pré definidas que a narrativa havia de ser livre, ele prontamente me perguntou: Posso ser o próximo? Respondi positivamente. Ele ficou me olhando de longe e esperando. Após concluir aquela conversa sentei-me no corredor fora da cela da ala dos trabalhadores e começamos a conversar.

Quando me contou sobre como era o cotidiano da cadeia antes da nova gestão e após a mesma, citou um momento em que ouvia no seu radinho de pilha a música "Barril de Pólvora" do Demonstro. Para explicitar o que o Rap já faz há muito tempo, apresentamos abaixo a narrativa Charles Stanley,

Eu vim de Cuiabá para Rondonópolis em 2000 com sete anos de idade. Eu, minha mãe e meu pai. Foi aí que tudo começou... Nova cidade, novas escolas, nova região e assim também novas amizades. Foi aí que começou a má influência. A partir delas comecei a experimentar a maconha, o cigarro e a partir dessa nova vida comecei a deixar de lado minhas obrigações, comecei a faltar aula, deixar de cumprir com as minhas obrigações dentro de casa, e eu tinha que fazer por que meu pai trabalhava e chegava só à noite. Enquanto isso minha mãe passo a passo ia ao abismo, pois começou a se embriagar no álcool e isso acabou prejudicando o casamento. O convívio familiar, começou a acabar, o amor o carinho a atenção. Foi isso aí que começou a fazer eu querer buscar um refúgio em meio as más influências dos amigos junto com o consumo alto e cada vez mais alto de drogas. Foi junto com esses camaradas que aos poucos foram morrendo um após o outro que comecei a praticar pequenos roubos até chegar a um estado mais profissional no crime, mas o fim sempre é o mesmo, ou é cadeia por muito tempo ou a morte ou cadeira de rodas. Não existe meio seguro para praticar esses atos que levam a morte. Por isso eu Charles venho fazendo mudanças na minha vida pessoal. $\mathrm{O}$ uso de drogas na época era uma fuga da minha realidade, 
Artigo original

Hegemonia - Revista Eletrônica de Relações Internacionais do Centro Universitário Unieuro

ISSN: $1809-1261$

UNIEURO, Brasília, número 16, 2015, pp. 22-45.

mas não acredito que foi isso que me levou para o crime. Entrei nessa mais por causa das más influências mesmo. Hoje estou com 3 anos e 6 meses aqui. Quando cheguei fui direto para ala dois, dos evangélicos e fiquei lá 2 anos, tive que me adaptar na tora pois a disciplina interna la é muito forte. Se acaso chegasse uma proposta de ir pra uma outra ala que não tivesse essas normas e regras, seria mais de $70 \%$ que ia sair de lá . Mais a realidade não é assim...Não é bem assim que funciona o sistema, você tem que demonstrar confiança para ganhar confiança e oportunidades, assim como essa minha de trabalhar aqui na ADM (administração), aqui a gente fica na disposição dos agentes para trabalhos como pintura, cozinha, pegar o lixo, serviços gerais. Eu comecei trabalhando na escola da cadeia ajudandoos professores, até ir ganhando confiança e a chance de trabalhar aqui. Logo vou quitar minha pena com a justiça e obter a minha liberdade e cumprir com meus direitos e deveres. Hoje tenho vários sonhos e objetivos para começar tudo de novo. Viver a liberdade!

Registrar a história de Charles Stanley, faz parte da estratégia, construída junto ao grupo de Pesquisa "Observatório: Poder, Cultura e Contemporaneidade, de construir um arquivo de história oral, onde outras perspectivas sobre a história do sistema prisional sejam registradas, afim de quebrar com as metanarrativas, que em geral, apresentam uma escrita de vultos e heróis, relegando o saberes e etimologias ao esquecimento.

A Penitenciária da Mata Grande passou recentemente por uma reestruturação que não possui registros (ao menos não temos conhecimento de sua existência), a não ser através desta escuta que realizamos. Esta reestruturação é compreendida de maneira diferente entre prisioneiros e agentes, e consideramos importante tornar este acontecimento conhecido. $O$ fragmento da narrativa de Charles pode ensinar a este respeito: 
Artigo original

Hegemonia - Revista Eletrônica de Relações Internacionais do Centro Universitário Unieuro

ISSN: $1809-1261$

UNIEURO, Brasília, número 16, 2015, pp. 22-45.

A história aqui se divide em antes e depois da cadeia ser "fechada". Alguns anos atrás a cadeia era "aberta", as alas tinham contato com as outras e existiam regalias que não existe mais, como por exemplo, geladeiras, som grande, DVD, diversos freezers para manter sorvete gelando, aqui era conhecido em todo meio penitenciário do estado como "shopping Mata Grande" por causa da "fofolândia", das regalias que os presos adquiriram com o tempo. Nessa época não tinha como a polícia (agentes) falar: não pode! Era tudo conversado e existiam os benefícios como jogar bola, alguns passeios, etc. Hoje isso tudo acabou, depois que mudou a direção isso mudou. A cadeia foi fechada, as alas não se comunicam entre si, os agentes têm controle bem maior sobre o preso, pararam também de acontecer algumas mortes das quais muitos eram inocentes e poucos eram culpados, era cada qual com sua sentença feita pela própria maioria. Hoje esse novo procedimento não permite isso mais...prá uns foi bom prá outros foi ruim, mas acontece que hoje tem mais oportunidade pra trabalhar e ter a remissão de pena e principalmente não acontecem mais essas violências e mortes que aconteciam aqui蕰

Sobre o conteúdo da música "Barril de Polvora", sobre o contexto em que foi criada, Charles Stanley faz a seguinte consideração:

A musica foi escrita no período em que a cadeia era "fechada" portanto muitas coisas que aconteciam,como já disse anteriormente, e que é relatada na musica, já não acontece mais, como por exemplo os versos: is pontiagudos"; is isedma reunião é formada entre celas rivais, objetivo imperar a paz (imperar a paz o caralho), uma emboscada na certa era pra ser três, somente um morreu na cela"唰 $\quad$ A muúica é uma fase que aconteceu, a fase passou mas ela fica na história relatada da Mata Grande, por que nem um outro ousou fazer uma letra sobre a Mata Grande o MC colocou o talento dele em ação, mostrou como que era a 
Artigo original

Hegemonia - Revista Eletrônica de Relações Internacionais do Centro Universitário Unieuro

ISSN: $1809-1261$

UNIEURO, Brasília, número 16, 2015, pp. 22-45.

realidade aqui em determinada época. Mas nem tudo que fala na música é passado, tem várias partes que eu me identifico, e acho que outros presos também como, por exemplo, os versos: mãe que é mãe não quer ver o fim do seu filhoisgja ele bandido pra ela é um bom

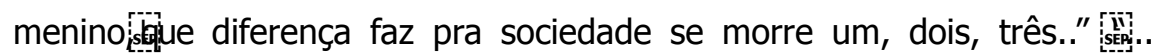
falando sobre o que tá rolando, isplanejar mais uma fuga por debaixo dos panos se tentar fugir e não conseguir mas continua tentando.." Ontem mesmo houve uma tentativa de fuga aqui frustrada pelos agentes penitenciários, por isso dá pra ver o quanto a música é atual também. Eu não penso em fugir não, por que na justiça é assim ou se paga cedo ou se paga tarde e prá mim essa vida de fuga acaba sendo mais um caminho errado tomado que vai me atrasar nos meus objetivos e metas... A parte que mais me identifico com a musica são essas um abraço apertados vontade de lutar sair do seu ladóspois a saudade é a única coisa que restâjátá ter força de vontade querer sair o mais depressads quando a sirene toca, fim da visita dis na mente o semblante

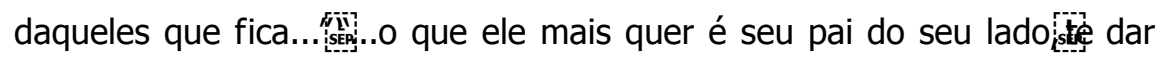
uma força reconstruir o barracos ser levado pra escola. semanas com o pai bater uma bolds cumprida em liberdade pra seguir a sua vida.... saudade é a que mais dói e mais faz a gente querer estar lá fora.. Outro verso que me identifico muito é esse: rádio de pilha的 Por que no meu radinho de pilha sempre escutava diariamente, assim como se fosse um meio de inspiração uma musica que falava muito comigo, me identificava realmente que era "Vida loka também ama" do Trilha Sonora do Gueto, ouvia muito também Racionais, Facção Central, o próprio Demonstro, Radio local, tinha um programa que era o Programa de Índio que era massa (risos) rolava de tudo naquele radinho: Ao deitar na "jega"1 ligar o som de pilha, ouvir uma música, refletir é uma válvula de escape pra mim, e isso que acaba alimentando sonhos, a luta, objetivos, metas, que após passar do muro só colocar em pratica assim como vários outros aqui, cada um na sua caminhada: A Musica Barril de Pólvora, como já disse relata uma 
Artigo original

Hegemonia - Revista Eletrônica de Relações Internacionais do Centro Universitário Unieuro

ISSN: $1809-1261$

UNIEURO, Brasília, número 16, 2015, pp. 22-45.

história desse lugar, conta realmente a realidade aqui em determinada época, e ainda hoje tem muitas partes da musica que me identifico e que fala da realidade do preso hoje em dia. Acredito que muitos outros presos se identificariam com as mesmas ou outras partes da música, mas com certeza ela é uma grande música que representa as realidades do preso.

Charles, e todos os demais prisioneiros com que temos nos encontrado durante a realização da pesquisa "Diagnóstico dos Fazeres e Poderes-Saberes que Constituem a Existência no Centro Sócioeducativo e Prisões de Rondonópolis MT", têm os corpos como alvos constantes do biopoder. Estes homens afirmam não conhecer qualquer publicação que conte a história da Mata Grande e de seus moradores, seja por qual perspectiva for. Ora, não estamos preocupados em construir uma história institucional, preocupada com fundadores e grandes nomes, pelo contrário, queremos diagnosticar o modo como a vida se articula neste território do isolamento. Objetivamos ainda compor um arquivo de história oral, onde homens privados de liberdade, considerados ordinários e monstros, como sugeriu Foucault, possam falar em seu próprio nome e registrarem sua assinatura.

Este é um trabalho experimental, que não apresenta conclusões, nem possui uma verdade para anunciar. O que compomos é uma cartografia dos afectos, daqueles que se manifestam nos homens e em suas relações com os outros, com as coisas, com o mundo.

Ora, sabemos que nosso olhar é selecionador. Que não podemos captar a totalidade do vivido, nem daquilo que é vivido por um homem, tampouco do que ocorre em nosso tempo. Ainda assim reivindicamos o direito de tratar de nosso tempo e lugar, à nossa maneira. Nosso olhar elegeu como foco as experiências dos prisioneiros, como aquilo sobre o que queremos pensar, afinal na hierarquia social que permeia a prisão, eles são os mais silenciados. 
Artigo original

Hegemonia - Revista Eletrônica de Relações Internacionais do Centro Universitário Unieuro

ISSN: $1809-1261$

UNIEURO, Brasília, número 16, 2015, pp. 22-45.

Considerando esta ausência de registro histórico da Mata Grande, a música "Barril de Pólvora" do grupo de Rap Rondonopolitano Demonstro, apresenta muito mais que uma descrição do cotidiano no interior dessa instituição de fechamento, posto que juntamente com a narrativa de um detento, morador do mesmo cenário que a musica retrata, constrói uma parte legítima e original da historia desse lugarisíg:

O Rap nasceu de um movimento que sempre andou na contra mão do sistema capitalista e de suas relações de opressão. Segundo Mano Brown "o Rap é uma brecha no sistema" (SCANDIUCCI, 2006). O Hip Hop se originou nas periferias e teve como principal discurso o relato do cotidiano, vivências, problemas e denúncias das mazelas produzidas pelas relações de poder opressoras atuantes sumariamente sobre jovens negros de periferia.

A instituição Prisão tem funcionado de modo à privar de liberdade, a por em afastamento social aqueles que não são "domesticados", pois segundo Michel Foucault:

\begin{abstract}
Uma coisa, com efeito, é clara: a prisão não foi primeiro uma privação de liberdade a que se teria dado em seguida uma função técnica de correção; ela foi desde o inicio uma "detenção legal" encarregada de um suplemento corretivo, ou ainda uma empresa de modificação dos indivíduos que a privação de liberdade permite fazer funcionar no sistema legal. Em suma, o encarceramento penal, desde o inicio do século XIX, recobriu ao mesmo tempo a privação de liberdade e a transformação técnica dos indivíduos.
\end{abstract}

Cabe ainda destacar que o presente artigo não tem um compromisso com o estabelecimento de uma verdade, pensamos que não há verdade a ser compromissada, assim como no Rap pretendemos divulgar o discurso daqueles que via de regra são silenciados e através do registro de suas narrativas legitimálos como agentes de produção de discurso histórico sobre determinado espaço e 
Artigo original

Hegemonia - Revista Eletrônica de Relações Internacionais do Centro Universitário Unieuro

ISSN: $1809-1261$

UNIEURO, Brasília, número 16, 2015, pp. 22-45.

tempo.

Ao colocar no mesmo espaço escritural a a letra da musica "Barril de Pólvora" do grupo Demosntro e as narrativas de Charles Stanley, apresentamos um viés, uma perspectiva, um olhar sobre a história desse presídio, concomitantemente com a historia do grupo Demonstro e de Charles, pois é necessário que esses sujeitos possam ser também sujeitos da própria historia e terem seus discursos legitimados.

\section{REFERÊNCIAS BIBLIOGRÁFICAS}

ssp

ANDRADE, Elaine Nunes de. Movimento negro juvenil: um estudo de caso sobre jovens rappers de São Bernardo do Campo. Dissertação de Mestrado, São Paulo, FFLCH-USP, 1996世:

CASSEANO, Patrícia, ROCHA, Janaína e DOMENICH, Mirella. Hip hop - A periferia grita. São Paulo, Fundação Perseu Abramo, 2001:

DELEUZE, Gilles. Conversações. Ed.34, 1992"

Mil platôs: capitalismo e esquizofrenia - vol. 5/ Gilles Deleuze e Félix Guattari. São Paulo. Ed. 34, 1997.

DU RAP, André e ZENI, Bruno. Sobrevivente André du Rap. São Paulo, Labortexto Editorial, 2002

FOUCAULT, Michel. Microfisica do Poder. Rio de Janeiro: Graal, 1979世

isters Vigiar e Punir: Nascimento da Prisão. Petrópolis: Vozes, 1987 is 2010

SCANDIUCCI, Guilherme. Cultura hip hop: um lugar psíquico para a juventude negro-descendente das periferias de São Paulo. Imaginario, São Paulo, v. 12, n. 
Artigo original

Hegemonia - Revista Eletrônica de Relações Internacionais do Centro Universitário Unieuro

ISSN: $1809-1261$

UNIEURO, Brasília, número 16, 2015, pp. 22-45.

12, jun. 2006 . Disponível em http://pepsic.bvsalud.org/scielo.php?. acessos em 30 maio 2015.

SCHOBER, Juliana. Hip-hop: das seções policiais para os cadernos culturais dos jornais. Cienc. Cult. [online]. 2004, vol.56, n.2, pp. 54-55. ISSN 2317-6660.

inliki IUNFO, Nelson. (em http://periferianacional.blogspot.com.br/2008/10. Acesso em: 21 Abril 2015.

ZENI, B. O negro drama do rap: entre a lei do cão e a lei da selva, 2004. 18, n. 50, 